\title{
USO DE EXPERIMENTOS DE BAIXO CUSTO NA QUEDA DE PARADIGMAS NO ENSINO TRADICIONAL DA QUÍMICA
}

\section{ARTIGO DE REVISÃO}

SOUZA, Kerollim Oliveira Gierts de ${ }^{1}$

ROQUETO, Marco Antônio ${ }^{2}$

SOUZA, Kerollim Oliveira Gierts de. ROQUETO, Marco Antônio. Uso de experimentos de baixo custo na queda de paradigmas no ensino tradicional da química. Revista Científica Multidisciplinar Núcleo do Conhecimento. Ano 05, Ed. 08, Vol. 13, pp. 101-115. Agosto de 2020. ISSN: 2448-0959, Link de acesso: https://www.nucleodoconhecimento.com.br/educacao/ensino-tradicional

\section{RESUMO}

A educação pública no Brasil é alvo de várias críticas, pois o ensino de nível médio se mostra insuficiente para a preparação dos discentes para o ensino superior, o mesmo problema acontece com a formação de docentes, devido a desvalorização da profissão, conforme os anos passam, aumenta a carência de profissionais do ramo. No ensino superior, sobretudo nas Ciências Exatas, não há muita procura de especialização para atuar na área. $O$ ensino da química tem se tornado cada vez mais desmotivador para os estudantes. Uma solução viável para queda dos paradigmas envolvendo o ensino da química seria o uso de aulas práticas envolvendo experimentos que se enquadram no conteúdo das aulas, com materiais de fácil acesso que se relacionam com cotidiano do aluno. Deve-se levar em conta o desinteresse dos estudantes e assim tentar aproximá-los da química. Os experimentos de baixo custo são uma grande alternativa para que isso ocorra, pois

\footnotetext{
${ }^{1}$ Bacharel e Licenciada em Química.
}

2 Orientador. Mestrado profissional em Mestrado em Tecnologia Ambiental. Especialização em Química. Graduação em Química. Graduação em Ciências. 
desperta nos alunos a curiosidade sobre o assunto. A química torna-se aliada que os alunos podem utilizar no seu aprendizado multidisciplinar. Cabe ao docente sair de sua zona de conforto e experimentar diversas metodologias que ajudem a melhorar a educação brasileira. O objetivo desta pesquisa é diminuir a dificuldade que os discentes possuem na disciplina de química, quebrando certos tabus envolvidos na área, e aproximar os alunos dos liceus, criando um ambiente mais descontraído.

Palavra-chave: Química, aulas experimentais, problemas na educação, materiais de baixo custo.

\section{INTRODUÇÃO}

A Educação Brasileira é alvo de muitas críticas, sendo um ramo desvalorizado pelas pessoas. Mas esta realidade está começando a mudar, a população começou a conscientizar que a base para melhorias no país é a educação. Segundo Schnetzler (2002), a desvalorização dos profissionais da educação acarreta a baixa procura dos cursos de graduação de licenciaturas que resulta na falta de professores, principalmente na área de exatas, pois a ciência exata é mal vista por muitos, como uma área complicada que não nutre um futuro desejável. Existem também os problemas governamentais que não reconhecem que a educação é uma das bases da estrutura brasileira, admitindo-a como algo primordial. Entretanto há várias propostas de diretrizes para a educação, mas deixam dúvidas se irão progredir ou retardar esse processo.

Além dos problemas governamentais, existem também os problemas do dia a dia do aluno que os impedem de ter bom desempenho em sua vida escolar. Dependendo da cultura que o discente convive fora da escola, terá repercussão em suas atitudes em sala de aula. Bairros carentes possuem uma realidade totalmente diferente de outras classes mais altas, nestes bairros existem problemas de prostituição, tráfico, gravidez na adolescência, abuso sexual, entre outros, geralmente os alunos não possuem perspectivas futuras, são raras as exceções. Já em bairros de classe mais favorecidas os jovens possuem outra visão, a mentalidade das pessoas é de um futuro melhor para si e para seus filhos, e como a educação pública no Brasil está em decaimento 
optam por escolas particulares, pois em sua maior parte, seu nível de aprendizado é mais alto. Para a educação pública se edificar deve ter uma junção entre o apoio governamental e a população, não haverá melhorias sem esses dois fatores se associarem.

De acordo com Bueno et al. (2008), para amenizar estes problemas deve ocorrer uma mudança de metodologias utilizadas pelos professores. Uma alternativa viável seria o uso de aulas práticas utilizando materiais de baixo custo. Tais experimentos são responsáveis em aproximar a química do aluno, sendo importante salientar que carece ao docente apresentar essas atividades, demonstrando que a química está presente em tudo que nos cerca e relacionando-a com o conteúdo a ser lecionado. Com isso, os alunos desenvolvem certas competências em sala de aula como trabalho em equipe, raciocínio lógico, boa comunicação, entre outras. Além disso, desenvolve o pensamento crítico do aluno, tornando-o um ser pensante capaz de ser protagonista de sua própria educação.

O presente trabalho foi realizado através de revisões bibliográficas com o objetivo de diminuir as dificuldades que os discentes possuem na disciplina de química, quebrando certos tabus envolvidos na área e aproximando os alunos dos liceus, criando um ambiente mais descontraído, que desenvolva o desejo do saber.

\section{PROBLEMAS NA EDUCAÇÃO PUBLICA BRASILEIRA}

A educação pública no Brasil é alvo de várias críticas, o ensino de nível médio mostrase insuficiente para a preparação dos discentes para o ensino superior, no qual os vestibulares de universidades públicas exigem além da capacidade dos adolescentes. (Goldemberg, 1993). De acordo com Rocha (2016) os problemas não se originam somente da ajuda dos nossos governantes, também surgem através dos alunos, como distúrbios comportamentais causados por problemas familiares, econômicos, sociais; segundo o sociólogo francês Pierre Félix Bourdieu, estas bagagens que os alunos trazem á sala de aula, denomina se o Capital Cultural, no qual ele afirma que o capital cultural é adquirido de acordo com as condições culturais e sociais em que as famílias 
se encontram, pois com o desenvolvimento dos jovens geram características do meio em que vivem.

Nos anos 60, Bourdieu defendeu que uma família que dispõe de certa estrutura social, absorve tais características que a sociedade estipula para ele dentro da sua classe social, e mantendo estas particularidades dentro dos mais diversos setores que irá atuar (NOGUEIRA e NOGUEIRA, 2002). Com isso este Capital Cultural tem uma comoção no âmbito escolar, para Bourdieu, esta abordagem beneficiaria as instituições de ensino facilitando o aprendizado desde que seja referencias cultas e adequadas, servindo de ligação com outras estruturas sociais, já para crianças mais desfavorecidas convivendo neste ambiente, significaria reeducação familiar, porém crianças com dificuldades de aprendizado e com problemas familiares, soaria de forma estranha e alarmante (NOGUEIRA e NOGUEIRA, 2002). Segundo Bourdieu:

A bagagem herdada por cada indivíduo não poderia ser entendida, no entanto, simplesmente, como um conjunto mais ou menos rentável de capitais que cada indivíduo utiliza a partir de critérios definidos de modo idiossincrático. Como já foi dito, segundo Bourdieu, cada grupo social, em função das condições objetivas que caracterizam sua posição na estrutura social, constituiria um sistema específico de disposições para a ação, que seria transmitido aos indivíduos na forma dos hábitos. A ideia de Bourdieu é a de que, pelo acúmulo histórico de experiências de êxito e de fracasso, os grupos sociais iriam construindo um conhecimento prático (não plenamente consciente) relativo ao que é possível ou não de ser alcançado pelos seus membros dentro da realidade social concreta na qual eles agem, e sobre as formas mais adequadas de fazê-lo (NOGUEIRA e NOGUEIRA, 2002, p.22).

\section{PROBLEMAS EM RELAÇÃO À DOCÊNCIA}

Os problemas da educação no Brasil devem se também a empecilhos com os docentes, conforme Savani (2009) citou; um dos obstáculos é a falta de condições no local de trabalho, remuneração baixa comparando á sua carga horaria excessiva, gerando desmotivação para passar seus ensinamentos aos alunos. Tais problemas diminuem a procura desta ilustre profissão, havendo escassez de professores, principalmente nas áreas de natureza exatas. Conforme os anos passam, surge carência até de profissionais docentes no ensino superior. No caso das Ciências 
Exatas, não possui muita demanda na procura de especialização, em concordância com Schnetzler (2002) à quantidade de pessoas cursando mestrado e doutorado em química vem diminuindo com o tempo, conforme citado no Quadro 1, já o Quadro 2 representa a região e quais universidades que mais contribuíram para tal fato.

Quadro 1:

\begin{tabular}{|l|l|l|}
\hline Período & M & D \\
\hline 1971 a 1980 & 4 & 1 \\
\hline 1981 a 1990 & 25 & 5 \\
\hline 1991 a 2000 & 44 & 23 \\
\hline 2001 & 4 & 3 \\
\hline TOTAL & 77 & 32 \\
\hline
\end{tabular}

Fonte: Quantidade de pessoas cursando Mestrado e Doutorado, segundo Schnetzler, $2002<$

Quadro 2:

\begin{tabular}{|l|l|}
\hline Sudeste (62) & Sul (28) \\
UNICAMP (30) & UFSC (8) \\
UFRJ (8) & PUC-RS (7) \\
USP (7) & UFRGS (6) \\
UFMG (5) & UNIJUÍ (4) \\
UFScar (3) & UFSM (1) \\
FGV-RJ (3) & UNISINOS (1) \\
CEFET-MG (2) & UFPR (1) \\
\hline
\end{tabular}




\begin{tabular}{|l|l|}
\hline UNESP (1) & Centro-Oeste (9) \\
UNIMEP (1) & UnB (7) \\
IMES (1) & UFMT (2) \\
PUC-RJ (1) & Norte/ Nordeste (3) \\
& UFRN (2) \\
& UFC (1) \\
\hline
\end{tabular}

Fonte: Universidades que mais contribuíram para os cursos de Mestrado e Doutorado por região, segundo Schnetzler, 2002.

Como é observado nos quadros acima, são poucos profissionais que chegam a cursar doutorado e mestrado, principalmente na região do Norte/ Nordeste, e com estes dados podemos considerar que futuramente faltarão educadores na área de exatas, essencialmente em ciências por todo o país.

\section{ENSINO DA QUÍMICA NO COTIDIANO}

A ciência, em geral, é ensinada desde o ensino fundamental, Daher et al. (2016) salienta que o ensino da ciência, desde o inicio do aprendizado ajuda inserir a criança na sociedade, capaz de desenvolver o processo cognitivo, mas também, a entender e a questionar atitudes ambientais, culturais e sociais. Já no ensino médio, a ciências da natureza é dividida em: Química, Biologia e Física, na qual cada disciplina é repassada de forma mais detalhada e complexa. Em harmonia com Bueno et al. (2008) o ensino da Química é aquela que proporciona ao aluno, o conhecimento da matéria, envolvendo reações e transformações de tudo que nos cerca, assimilando o que está presente no dia a dia, desde o surgimento de novas tecnologias que são capazes de revolucionar as ciências a descobertas de novas substâncias para facilitar a vida humana, desta forma a Química, como outras ciências é essencial para o saber. 
Segundo Da Silva (2010) o ensino da química tem se tornado cada vez mais desmotivadora para os discentes, pois ela é vista como uma disciplina maçante e cansativa, com memorização de fórmulas, utilização de cálculos excessivos, e a maior parte das aulas são com base em livros didáticos e apostilas ultrapassadas, inclusive a didática dos professores se tornou muito obsoleta, não havendo uma troca de conhecimento entre professor e aluno. Da Costa Ramos (2008) deixa claro que os professores não se arriscam para melhorar o ensino e também se acomodaram, escolhendo o mais fácil do que o caminho correto:

Muitos professores ainda preferem desenvolver suas aulas baseados em estratégias que estejam mais ao seu alcance, e que thes proporcionam maior grau de segurança. Portanto, procuram optar pelas tradicionais aulas expositivas e pelo constante uso dos livros didáticos, ao invés de utilizarem novos métodos de ensino, mais ousados, capazes de estimular o diálogo e a interação em sala de aula. (DA COSTA RAMOS, 2008, p. 318).

De acordo com Bueno et al. (2008), a Química é uma disciplina pouco complexa, que não necessita de pessoas com excelente nível de inteligência, nem de equipamentos valiosos, basta o professor se adequar na realidade do aluno:

Independentemente das perspectivas construtivas do processo de aprendizagem tem sido proposto que as atividades de ensino empregadas nas aulas de diferentes disciplinas escolares sejam planejadas de modo a aproveitar, complementar, desenvolver e transformar as ideias, teorias e conhecimentos que os alunos trazem consigo (BUENO et al., 2008, p. 3).

Ao citar o ensino da química, devemos ressaltar o ensino/aprendizagem que ajuda o aluno á possuir consciência socioeconômica da disciplina de acordo com os tempos atuais, ou seja, relacionar a química com o surgimento de novas criações, pois estamos vivendo na era da modernização, no entanto, assuntos interdisciplinares não estão sendo inseridos na sala de aula por não possuir docentes preparados para tal fato. Com o intuito de ensinar a disciplina com ótima qualidade é preciso que a relação do professor, aluno e o material de estudo estejam em harmonia com as relações atitudinais a serem desenvolvidas, para que isto ocorra é necessário ter a confiança e o dialogo do aluno/professor com finalidade de incessante desenvolvimento crítico e 
intelectual do docente/discente (ROCHA, 2016). Uma possível solução viável para queda dos paradigmas envolvendo o ensino da química seria o uso de aulas praticas envolvendo experimentos que se enquadram no conteúdo das aulas e com materiais de fácil acesso que relacionam o cotidiano do aluno (GUIMARÃES, 2009).

\section{AULAS EXPERIMENTAIS E SEUS BENEFÍCIOS}

As aulas de experimentação, o aluno consegue relacionar o conteúdo com o seu dia a dia (GUIMARÃES, 2009). Esta ideia corrobora com Bueno et al. (2008), na qual afirma que não pode ocorrer a separação da teoria com a prática, pois é neste caminho que o aluno consegue associar os conteúdos com o sua rotina. Mas isso depende das condições das instituições de ensino, são de muita importância que as escolas tenham laboratórios equipados com reagentes, vidrarias, e outros utensílios próprios para o local, porém não é essa a realidade dos liceus, muitas escolas não possuem nada, e quando a possuem, estão em péssimas condições de uso.

Conforme Guimarães (2009) salienta: "A experimentação pode ser uma estratégia eficiente para a criação de problemas reais que permitam a contextualização e o estímulo de questionamentos de investigação". No entanto, os professores que optam pelas aulas práticas devem ter como finalidade a aprendizagem do aluno e não os conhecimentos adquiridos pela experimentação (GALIAZZE et al., 2004), em conformidade com Guimarães (2009), o professor deve abordar o conteúdo de forma expositiva, ajudando os discentes adquirir o aprendizado esperado pelo conteúdo, pois trabalhando os questionamentos dos alunos ajuda a junção de informações antes de receber novos conhecimentos, corroborando com esta ideia Alves de Lima (2005), afirma que nos dias atuais as aulas experimentais quando efetuadas não ajudam os alunos a se desenvolverem:

[...] as atividades experimentais quando realizadas, têm como objetivo verificar conceitos já lecionados, se tornando meramente uma coleta de dados, não levando em conta a interpretação dos resultados, não tendo características de um processo investigativo e não fazendo aflorar alguns objetivos educacionais do processo cognitivo: "conhecer, compreender, aplicar, analisar, sintetizar e avaliar" (ALVES DE LIMA, et. al. 2005 Apud DOMIN, 1999, p.1). 
Em harmonia com Dias (2016), existem três tipos de aulas experimentais:

Demonstrativo: No qual o aluno observa o professor realizando o experimento, isto acontece quando os recursos disponíveis são limitados, não havendo possibilidade de todos os discentes realizarem o ensaio (DIAS, 2016).

Verificativo: Geralmente o aluno já conhece o resultado esperado e realiza a analise para verificação do resultado, este tipo de experimento serve para verificar a autenticidade ou a exatidão do teste, esta metodologia experimental tem como finalidade desenvolver a capacidade do aluno de observar, analisar e questionar o que está acontecendo, esse método é bastante utilizado em sala de aula, pois aproxima o aluno de sua realidade (DIAS, 2016).

Investigativo: Com ajuda do professor, o aluno surge com situações problemas, cabe a ele criar hipóteses, surgir com prognósticos de resultados mais viáveis e a chegada de conclusões, esta metodologia transforma o aluno de passivo para ativo, deixandoo protagonista de seu aprendizado (DIAS, 2016).

As aulas de experimentação, normalmente são apresentadas de forma demonstrativa, no qual o aluno observa somente o fato ocorrido, mas não se associa o porquê da reação, e nem o porquê que estuda determinado conteúdo, sendo assim, não desenvolve suas competências e também desmotiva o aprendizado, fazendo com que a química se torne uma disciplina indesejável. Como muitas escolas do ensino publico não possuem estrutura suficiente para oferecer esta vivência aos discentes, seria uma alternativa viável material de baixo custo para alterar esta realidade dos discentes. De acordo com Benite et al. (2009), pode se utilizar materiais recicláveis como sucata ou materiais que todos dispõem em casa, como por exemplo, um relógio de pulso ou um simples repolho, cabe ao professor estipular e granjear o material que será utilizado em sala de aula. 


\section{EXPERIMENTOS}

Existem certos tipos de experimentos realizados em laboratórios que podem acontecer em sala de aula utilizando materiais acessíveis de acordo com o conceito em que o docente esteja abordando. Em seguida serão citados alguns experimentos que abordam alguns conteúdos que possam ser apresentados em sala de aula de maneira simples e direta.

\subsection{PH}

Para calcular pH em laboratório existem vários meios, como por exemplo, o uso de um equipamento (pHmêtro), papel indicador ou até mesmo soluções indicadoras (fenolftaleína, azul de bromotimol, alaranjado de metila e entre outras). Em sala de aula é fácil demonstrar com vários itens que os alunos possuem mais contato, como repolho roxo, jabuticaba, incluindo plantas como hortênsias que com suas flores demonstram se o solo é alcalino ou básico, enfim, existem vários meios do professor abordar o conteúdo relacionando ao dia a dia do aluno.

Como exemplo de um experimento, pode ser usada a uva como um indicador, no qual é preciso deixar suas cascas em repouso em álcool $1: 3(\mathrm{~m} / \mathrm{v})$ durante $24 \mathrm{~h}$ em temperatura ambiente, em seguida o extrato deve ser filtrado, e a solução estará pronta (TERCI e ROSSI, 2002). Os alunos poderão acrescentar este extrato nas soluções preparadas por eles mesmo, estas soluções devem apresentar diferentes pHs com caráter ácido e básico, utilizando reagentes como suco de limão, vinagre, Hidróxido de Sódio ( $\mathrm{NaOH}$ - Soda Cáustica), após o indicador reagir com as amostras, cada solução irá apresentar coloração diferente e os discentes deverão comparar as cores com a figura 1, no qual identificará o pH correto das substâncias. 
Figura 1: Diferenças de cores na escala de $\mathrm{pH} 0$ á 14, com extrato de uva como indicador

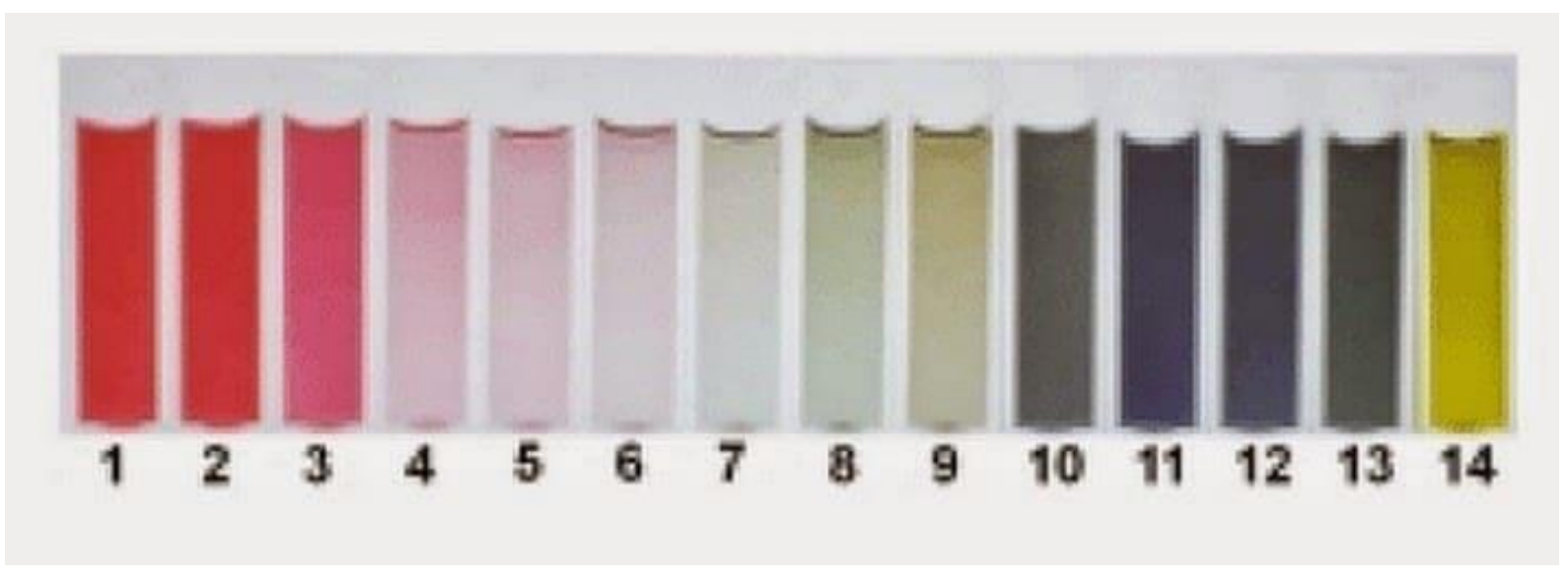

Fonte: TERCI e ROSSI, 2002.

Este conteúdo pode abordar diferentes temas em sala de aula, como o conceito de $\mathrm{pH}$ e $\mathrm{pOH}$, a maneira que é calculado sem ajuda de aparelhos, o caráter de substâncias diversificadas: ácida, base ou neutra.

\subsection{PLÁSTICO BIODEGRADÁVEL}

Na química orgânica existem vários tipos de testes que englobam uma diversidade de conteúdos utilizando materiais de fácil acesso, outro experimento a ser citado é o plástico fabricado com a batata, o professor pode abordar este assunto através das aulas que irá ministrar sobre polímeros. Segundo Thenório (2013), para a produção do plástico será utilizado os seguintes materiais:

- 4 batatas;

- 4 colheres de vinagre;

- 4 colheres de glicerina;

- Corante;

- Água.

O primeiro passo será fatiar as batatas e colocar em um liquidificador com um pouco de água, o suficiente para cobri-las, bater até se tornar uma mistura homogênea, em 
seguida filtrar a amostra e deixar o liquido em repouso por 2 horas, durante o tempo de descanso, irá ocorrer à formação de um precipitado branco em forma de pasta, escoar todo o líquido deixando somente o precipitado, logo após, em uma frigideira colocar duas colheres deste precipitado, acrescentando a glicerina, o vinagre, o corante e um copo de água, levar ao fogo até se tornar uma geleia, entornar está geleia em uma forma grande de maneira que esta substancia fique em uma camada uniforme e pouco espessa, deixar secar durante uma semana, para finalizar este plástico basta desgrudar a substancia da forma cuidadosamente, o plástico biodegradável estará pronto.

A explicação deste processo é simples, o precipitado branco formado na primeira etapa é o amido, que está presente na batata e também é à base do plástico, como as moléculas do amido possuem algumas ramificações, ao acrescentar o vinagre para que reaja com elas, ele facilita a formação do plástico, e a glicerina é adicionada para deixar este item mais maleável (THENÓRIO, 2013). O docente poderá explicar a química envolvendo o processo, e também desenvolver a consciência socioambiental do discente, relacionando os assuntos de reciclagens, materiais biodegradáveis, e pode estimular os alunos ao pensar, aguçar sua curiosidade, e os aproximar com a química do cotidiano.

\subsection{GASES E PRESSÃO ATMOSFÉRICA}

Este experimento é mais conhecido como ovo engarrafado, tem como objetivo mostrar ação da pressão atmosférica, através da atuação de um gás mediante a alteração de temperatura no ambiente em que se encontra (DIAS, 2016). Neste caso será preciso somente, um ovo cozido, uma garrafa com um gargalo que aproxime do diâmetro do ovo e uma caixa de fosforo, para realização desta atividade basta acender quatro fósforos e colocar dentro da garrafa, e imediatamente posicionar o ovo cozido e descascado em cima do gargalo, e pedir para os alunos observar o ocorrido.

Para os discentes compreender este teste, o professor deverá explicar que as moléculas de um gás estão afastadas umas das outras, e com o aumento de temperatura a velocidade das moléculas aumentam e se afastam ainda mais umas 
das outras. Neste experimento, no interior da garrafa está completo de $\mathrm{CO}_{2}$ (gás carbônico), e com o aquecimento as suas moléculas ficam mais distantes uma das outras, e quando diminui a combustão dos fósforos e a temperatura começam a cair às moléculas se aproximam e a pressão diminui, e como a pressão do lado externo é maior o ovo é empurrado para dentro (DIAS, 2016). De acordo com Dias (2016), o professor pode comentar outra situação semelhante que seria a água, que em temperatura ambiente ela se encontra em estado líquido e suas moléculas estão mais espaçadas, mas quando a temperatura diminui as moléculas se juntam transformando em estado sólido, já quando a temperatura se eleva, suas moléculas se distanciam ainda mais se tornando vapor, ou seja, estado gasoso.

\section{CONSIDERAÇÕES FINAIS}

A partir das argumentações precedentes, pôde-se observar que existem vários fatores que interferem na excelência da educação brasileira, e um desses fatores abordados no presente trabalho é a falta de docentes, pois esta profissão vem presenciando grandes dificuldades que diminui sua procura, que são a baixa remuneração, más condições de trabalho, carga horária excessiva, pouco investimento na educação, e principalmente a realidade dentro da sala de aula, na qual o professor suporta situações complicadas na relação professor e aluno, e na disciplina da química é mais incompreensível por ser vista como uma disciplina difícil e complexa. Também uma pequena parte dos problemas pode ser melhorada com a mudança de metodologias utilizadas pelos professores.

Estes docentes devem levar em conta o desinteresse dos estudantes e tentar aproxima-los com a química, os experimentos de baixo custo é uma grande alternativa para que isso ocorra, pois os alunos possuem curiosidades sobre o assunto, e despertando esta característica neles, a química acaba sendo uma aliada que os discentes podem utilizar no seu aprendizado multidisciplinar. E cabe ao docente sair de sua zona de conforto e experimentar diversas metodologias que ajude aprimorar a educação brasileira. 


\section{REFERÊNCIAS}

ALVES DE LIMA, Viviani; RIBEIRO MARCONDES, Maria Eunice. Atividades Experimentais no Ensino de Química: Reflexões de um grupo de professores a partir do tema eletroquímico. Enseñanza de las Ciencias, n. Extra, p. 1-4, 2005.

BENITE, Anna Maria Canavarro; BENITE, Claudio Roberto Machado. O laboratório didático no ensino de química: uma experiência no ensino público brasileiro. 2009.

BUENO, Lígia et. al. O ensino de química por meio de atividades experimentais: a realidade do ensino nas escolas. Segundo Encontro do Núcleo de Ensino de Presidente Prudente. São Paulo: Universidade Estadual Paulista-Publicações, 2008.

DA COSTA RAMOS, Luciana Bandeira; DA SILVA ROSA, Paulo Ricardo. O ensino de ciências: fatores intrínsecos e extrínsecos que limitam a realização de atividades experimentais pelo professor dos anos iniciais do ensino fundamental. Investigações em Ensino de Ciências, v. 13, n. 3, p. 299-331, 2008.

DA SILVA, José Luiz et al. A utilização de vídeos didáticos nas aulas de Química do Ensino Médio para abordagem histórica e contextualizada do tema vidros. Silva, p. 1, 2010.

DAHER, Alessandra Ferreira Beker; DE MATTOS MACHADO, Vera. ENSINO DE CIÊNCIAS NOS ANOS INICIAIS DO ENSINO FUNDAMENTAL: O QUE PENSAM OS PROFESSORES. Revista da SBEnBio - Número 9-2016

DIAS, Edelson de Jesus Sá. EXPERIMENTOS DE QUÍMICA ORGÂNICA UTILIZANDO MATERIAIS ALTERNATIVOS PARA APLICAÇÃO NO ENSINO MÉDIO. 2016.

DIAS, Iron Moreira. Uma proposta de roteiros experimentais para o ensino de química na $1 \underline{a}$ série do ensino médio em uma escola de educação do campo. 2016. 
GALIAZZI, Maria do Carmo; GONÇALVES, Fábio Peres. A natureza pedagógica das atividades experimentais: uma pesquisa no curso de licenciatura em química. 2004.

GOLDEMBERG, José. O repensar da educação no Brasil. Estudos Avançados, v. 7, n. 18, p. $65-137,1993$.

GUIMARÃES, Cleidson Carneiro. Experimentação no ensino de química: caminhos e descaminhos rumo à aprendizagem significativa. Química nova na escola, v. 31, n. 3, p. 198-202, 2009.

NOGUEIRA, Cláudio Marques Martins; NOGUEIRA, Maria Alice. A sociologia da educação de Pierre Bourdieu: limites e contribuições. Educação \& Sociedade, v. 23, n. 78, p. 15-36, 2002.

RICARDO, Elio Carlos. Educação CTSA: obstáculos e possibilidades para sua implementação no contexto escolar. Ciência \& Ensino (ISSN 1980-8631), v. 1, 2008.

ROCHA, Joselayne Silva; VASCONCELOS, Tatiana Cristina. Dificuldades de aprendizagem no ensino de química: algumas reflexões. XVIII ENCONTRO NACIONAL DE ENSINO DE QUÍMICA. VIII ENEQ, Florianópolis, SC, v. 25, 2016.

SAVIANI, Dermeval. Formação de professores: aspectos históricos e teóricos do problema no contexto brasileiro. 2009.

SCHNETZLER, Roseli P. A pesquisa em ensino de química no Brasil: conquistas e perspectivas. Química nova, v. 25, n. supl 1, p. 14-24, 2002.

TERCI, Daniela Brotto Lopes; ROSSI, Adriana Vitorino. Indicadores naturais de ph: usar papel ou solução?. Química Nova, v. 25, n. 4, p. 684-688, 2002.

THENÓRIO, Ibererê. Como fazer plástico de batata. 2013. Disponível em: $<$ https://www.manualdomundo.com.br/2013/10/como-fazer-plastico-de-batata/>. Acesso em: 12 out. 2018

Enviado: Fevereiro, 2020. 
Aprovado: Agosto, 2020. 